Gilles Saint-Paul is a professor at Universitat Pompeu Fabra and a fellow of the CEPR. He is grateful to the Bank of Spain and the Centre de Recerca en Economia Internacional, Universitat Pompeu Fabra, as well as Chris Waller and participants at the Federal Reserve Bank of Saint Louis annual conference, and seminar participants at the Bank of Italy, Rome and CEMFI, Madrid for helpful comments and suggestions.

\section{Assessing the Political Viability of Labor Market Reform: The Case of Employment Protection}

\author{
Gilles Saint-Paul
}

T

here is somewhat of a consensus among economists that labor market rigidities are responsible for high unemployment in Europe, and in particular for its most alarming aspects such as its long duration and high incidence on youth. Unemployment benefits lower the incentive for job search and increase wage pressure by insiders. Minimum wages price the least skilled out of the market. Firing costs deter hiring, thus reducing labor demand, and hamper the economy's ability to deal with uncertainty and structural change. This is why experts frequently recommend making the labor market more flexible, as is exemplified by the conclusions of the recent OECD Jobs Study (1995).

But, in practice, few of the remedies economists advocate pass the test of political viability. In 1994, an attempt by the French government to lower the minimum wage for young workers was followed by violent demonstrations, and the government eventually withdrew its reform proposal. In 1995, in order to be elected, a French presidential candidate put on its platform an increase in the minimum wage. In 1994, the Swedish government lost the elections because it had lowered the unemployment benefit replacement ratio from 90 percent to 80 percent. After reunification, the German government gave in to western unions' pressure and allowed eastern wages to converge rapidly to western levels, despite large productivity differentials and the need to restructure the eastern economy, which led to substantially higher unemployment rates in the East than in the West.

In my view, an understanding of the political determinants of labor market institutions is a crucial prerequisite for being able to implement structural reforms that are acceptable to those social groups that potentially may block these reforms.

While we believe that the set of institutions that prevail in many European countries form a coherent whole, given the complexity of the issue it is often more convenient to analyze these institutions separately from each other. In this paper we focus on employment protection legislation (also called "firing costs"). We want to know who gains and who loses from such regulation, and what will be the equilibrium level of employment protection. We abstract from other rigidities- we do not ignore them, but take them as given, ignoring that they, too, are the outcome of the political process.

Why firing costs rather than other institutions? This is partly a matter of taste and I have discussed other institutions elsewhere. ${ }^{1}$ But there are several reasons why employment protection is more rel evant than other rigidities when one deals with the political economy of reform. First, it is regularly pointed out by employers as one of the most severe constraints on their incentives to create jobs. Second, it is somewhat more renegotiable than minimum wages or unemployment benefits. Some reductions in firing costs have been observed in various countries in the eighties and nineties. We have not seen similar reductions in unemployment
1 For example, SaintPaul (1996a, b). 
compensation or minimum wage laws. Unemployment benefits are seen as part of the "welfare state" and attempts to reduce them often are interpreted as a first blow to the whole welfare state, while the minimum wage is often an untouchable symbol. ${ }^{2}$ Third, while firing costs' impact on employment is actually unclear, ${ }^{3}$ they clearly increase unemployment duration. If anything, the key difference between Europe and the United States is not so much the former's higher unemployment rate- which partly reflects composition effects and a greater incentive to register as unemployed-as Europe's much larger unemployment duration. ${ }^{4}$

Behind the political support for employment protection lies the existence of rents in favor of the employed, which arise due to imperfections in the labor market. We understand firing costs as a device to protect the rents of incumbent employees. The greater these rents, the greater their incentive to support protective measures.

We define the "rent" as the welfare differential between an employed and an unemployed worker. In a perfectly competitive labor market, this differential should be equal to zero, because any worker looking for a job would find one instantaneously at the going equilibrium wage. Thus, there would be no welfare difference between the employed and the unemployed. In practice, the employed have rents, that is, they are strictly better off than the unemployed. The size of these rents depends on their bargaining power (their ability to prevent the unemployed from underbidding them, which itself is affected by labor market institutions), and also how closely their work effort can be monitored by employers. The rent is a measure of how far wage setting is from competitive behavior; the higher the rent, the less competitive wage formation and

2 See Saint-Paul (1996b).

3 See, for example, Bentolila and Bertola (1990).

${ }^{4}$ See Cohen, Lefranc, and Saint-Paul (1997), Blanchard and Portugal (1998). the higher the natural rate of unemployment. M ost of the essence of labor market reform is about eliminating the rent. This is certainly true of any reform of the minimum wage and the bargaining process, or of any change that makes it easier for outsiders to compete with insiders: hiring rules, work rules, and many aspects of employment protection. Here, however, we take the workers' bargaining power as given, and consider what happens when people vote on a firing cost that does not directly affect their bargaining power.

Rents have important consequences for the political preferences of incumbent employees. This is because the rent tells us how much they lose if they lose their jobs, or how much they are willing to pay for keeping them. The greater the rent, the greater the aversion of insiders to unemployment and the greater the political support for employment protection legislation. Employment protection legislation is complex; it associates to each cause of firing a set of constraints imposed on the employer. These constraints include severance payments, administrative supervision, obligation to provide the displaced workers with job counseling and to give them priority over hiring by the same conglomerate, unions' right of scrutiny and appeal, etc. To some extent, these constraints increase the employee's bargaining power by making it more difficult for the employer to resist wage demands by refusing to employ the worker any longer. The direct effect of firing costs, however, is to make it more costly for the firm to adjust its labor force when facing a fall in demand. Because we want to isolate the pure employment protection effect of firing costs, we shall assume that it does not affect the workers' bargaining power.

Unlike my previous work on the same topic (Saint-Paul, 1993, 1997), this paper pays a lot of attention to the role of firing costs in the growth process when obsolescence - or "creative destruction" - is an important aspect of growth. In our vintage capital model, each match gradually becomes obsolete (because its productivity fails to catch up with the latest technology) until it is destroyed, at which time the worker becomes unemployed. We assume people vote between two levels of the firing cost (a "flexible" and a "rigid" one). In our model, firing costs increase the life span of any match by inducing firms to postpone the date of economic obsolescence. 
In voting in favor of employment protection, incumbent employees trade off lower living standards ( because employment protection maintains workers in less productive activities) against longer job duration. The support for employment protection will then depend on the value of the latter relative to the cost of the former. We highlight two key determinants of this trade-off: first, the workers' bargaining power; second, the economy's growth rate- more precisely its rate of creative destruction. Let us explain briefly the mechanisms that underlie the effect of these two parameters.

The rent. The value of longer job duration to incumbent workers is proportional to the rent, or equival ently, their bargaining power; long job duration would not be valued if the employed were not earning rents above the unemployed. The cost of job loss would then be zero, and so would the support for employment protection. This result tells us that there exists a "complementarity" between firing costs and other labor market rigidities to the extent that the latter increases workers' bargaining power.

One important consequence is the existence of complementarities across policy reforms. A comprehensive labor market reform attacks those rigiditiesone that increases workers' bargaining power at the same time that it reduces firing costs- is more likely to be successful than one that only tackles the latter aspect.

C reative destruction. Firing costs reduce the economy's average productivity by maintaining a fraction of the workforce in vintages that are older than the most up-to-date technology. In equilibrium, this ends up reducing wages and living standards. Now, this effect will be stronger, the greater the productivity gap between old vintages and new vintages, that is, the greater the growth rate. A higher growth rate consequently reduces the political support for employment protection legislation, because it increases its cost in terms of lower wages.

We show that the political support for firing costs typically comes from a fraction of the employed workers: those who work in matches that are not too old, nor too young. In the first case, workers are going to lose their jobs quickly; they are better off unemployed in a flexible society than employed in a rigid society. In the second case (which may be degenerate and reduced to an empty set), workers consider that the end of their job is pretty remote and are not willing to pay the cost of employment regulation.

We supplement our analytical reasoning with some evidence suggesting that increases in firing costs tend to occur at times when workers' weight in bargaining is high, and, conversely, reductions in firing costs take place when bargaining power is low. This is in accordance with our model.

\section{EMPLOYMENT PROTECTION IN A RENOVATING ECONOMY}

Let us consider a world with different vintages of capital. ${ }^{5}$ At any point in time $t$ there is a state-of-the-art technology that allows production of $a_{t}$ units of output with one unit of labor, where $a_{t}$ is assumed to grow at a constant exogenous rate $g$, so that $a_{t}=a_{0} e^{g t}$. There is free entry of firms (considered as hiring a single worker) in the state-of-the-art technology; but once a firm has entered, it cannot upgrade. It is stuck with the level prevailing at the time of entry.

If exit were costless, firms would enter the market for a very small amount of time and then disappear, because competition by new entrants would constantly drive wages up to the state-of-the art technology level, thus making any old plant unprofitable. We assume, however, that exit is costly so that in order to close at time T the firm pays a firing cost in terms of output, equal to $F a_{T} \cdot{ }^{6}$ We assume that this firing cost is wasted. Firing costs imply that un profitable plants, instead of closing, will continue until losses become so large that it is actually preferable to pay the firing cost and close the position. By the same token, for new jobs to be created, it must be the case that they run positive profits in the beginning of their lifetime,
${ }^{5}$ This is in a fashion somewhat similar to Caballero and Hammour (1994). Another option would be to rule out growth and assume that once in the market, firms suffer shocks to their productivity level, and that they can freely enter the market at the maximum possible level, as in Mortensen and Pissarides (1994) or Saint-Paul (1997).

\footnotetext{
${ }^{6}$ Dependence on the productivity trend implies that the firing cost grows at the same rate as the rest of the economy, and, therefore, does not become negligible relative to the surplus of a match.
} 
to compensate for the future losses associated with the firing cost. Therefore, wages cannot be as high as the state-of-the art technology level, contrary to what would happen absent exit costs.

Firms and workers can freely borrow and lend at the real interest rate $r$. We assume $r>g$, which guarantees that the present discounted value of income streams will be well defined.

Workers are homogenous and negotiate wages in an imperfectly competitive fashion, thus being able to raise their welfare strictly above their outside opportunity - that is, the welfare of an unemployed worker. Consequently, in equilibrium, there is a positive stock of involuntarily unemployed workers who wait to find a job created by a new entrant.

At any time the net value of a firm that entered the market at date $s$ is equal to the present discounted value of its profits minus the (discounted) firing cost it has to pay upon termination:

$$
\begin{aligned}
J(s, t)= & \int_{t}^{T(s)}\left(a_{s}-w(s, u)\right) e^{-r(u-t)} d u \\
& -F a_{T(s)} e^{-r(T(s)-t)}
\end{aligned}
$$

where $w(s, u)$ is the bargained wage between firms and workers at date $u$, which will be determined below.

The firm sets its exit time optimally by maximizing expression 1 with respect to $\mathrm{T}(\mathrm{s})$. The first order condition is:

$$
w(s, T(s))-a_{s}=(r-g) F a_{T(s)} .
$$

The left-hand side is the loss per period made by the firm while the right-hand side is the annuity value of the firing cost. Note that faster growth reduces the annuity value of the firing cost: As they are indexed on the economy's growth trend, postponing dismissal increases the value of the firing cost. This effect reduces the opportunity cost of firing today. ${ }^{7}$ Finally, the free-entry condition implies that the net value of the firm is zero at the time it enters the market:

$$
J(t, t)=0 .
$$

We now turn to wage determination. Our key assumption is that workers can appropriate a share of the surplus generated by the match gross of the firing cost. Formally, this is equival ent to

$$
w(s, t)=b a_{t}+\theta_{t} \varphi S(t)+\varphi a_{s},
$$

where $\varphi$ is the share of the gross surplus that the worker is able to appropriate, $b a_{t}$ is the income flow of an unemployed worker (for example, the unemployment benefits he is paid), $\theta_{t}$ is the probability per unit of time that an unemployed worker finds a job, while

$$
S(t)=\int_{t}^{T(t)} a_{t} e^{-r(u-t)} d u
$$

is simply the present discounted value of the firm's gross output.

The meaning of equation 5 is as follows. The last term is the fraction of the match's output appropriated by the worker. The first two terms are the worker's "alternative wage," or outside option, that is, the wage that would make him just indifferent between being unemployed and working for that firm. The first term represents the unemployed's flow of income, while the second term represents the contribution to his welfare of the future rents he will appropriate from his next jobs. It is larger, the greater the probability of finding a job and the larger the share of the surplus appropriated by the worker. ${ }^{8}$

The probability of finding a job, $\theta_{t}$, is the key endogenous variable that determines the adjustment of the labor market. Its equilibrium value is determined by the free-entry condition, equation 4 , that requires that the net value of a newborn firm be equal to zero. If the labor market were too tight, relative to that equilibrium value of $\theta$, wages would be too high and new firms' net value would be negative. Consequently, firms would not enter the market, which would reduce the jobfinding probability and push wages downwards to the point where the free-entry condition is met again. 


\section{EQUILIBRIUM}

We are now in a position to compute the equilibrium of our economy. To do so, we limit ourselves to a "steady state," that is, a balanced growth path where wages and output grow at rate $g$, while unemployment, labor market tightness $\theta$, and the duration of a job are constant. Let us call that constant duration $\mathrm{x}$.

To do so, we proceed as follows. First, note that the firm's present discounted output, in steady state, is simply equal to

$$
S(t)=a_{t} \frac{1-e^{-r x}}{r} .
$$

The term $\left(1-e^{-r x}\right) / r$ is simply the present discounted equivalent of a constant, unit flow of income over a time interval of length $x$. Substituting equation 7 into the wage equation 5 we get that

$$
\begin{aligned}
w(s, t)= & a_{t}\left(b+\theta \varphi \frac{1-e^{-r x}}{r}\right. \\
& \left.+\varphi e^{-g(t-s)}\right),
\end{aligned}
$$

where, as previously, the first two terms represent the alternative wage and the last term the rent earned on one's current job.

Using that condition, we can rewrite the optimal closing condition, equation 2, as

$$
\begin{aligned}
(\varphi-1) e^{-g x} & +b+\theta \varphi \frac{1-e^{-r x}}{r} \\
& =(r-g) F .
\end{aligned}
$$

This is a first equation that gives us a relationship between $x$ and $\theta$. This is a decreasing equilibrium relationship that tells us that a tighter labor market pushes wages up, thus forcing firms to close at an earlier time.

N ext, using the free-entry condition 4 along with the wage equation 5 and with equation 7 , then making use of equation 9 , we get a second equation that determines $\mathrm{x}$ :

$$
(1-\varphi)\left[\frac{1}{r}+\frac{g e^{-r x}-r e^{-g x}}{r(r-g)}\right]=F
$$

\section{Figure 1}

Equilibrium

Determination

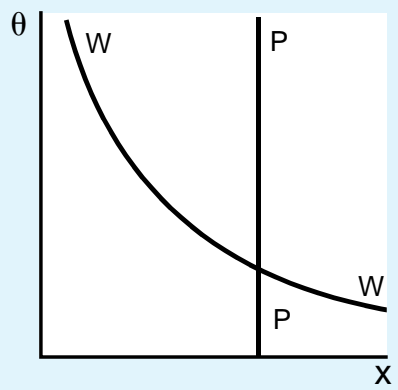

The left-hand side is the present discounted value of profits, gross of the firing cost, $^{9}$ and the right-hand side is equal to the firing cost. The equation tells us that under free entry the cumulated profits must exactly cover the firing cost. As long as $F<(1-\varphi) / r$, equation 10 defines a unique equilibrium value of $x$. If $F$ is greater than $(1-\varphi) / r$, then it is optimal for firms never to close, a case we rule out by assumption.

The equilibrium is determined in Figure 1 by the intersection of two schedules, a downward sloping schedule W W defined by equation 9 , and a vertical one PP defined by equation 10 .

The equilibrium has the following properties:

- An increase in $\varphi$, the workers' bargaining power, shifts PP to the right and WW downward (Figure 2a). Consequently, the duration of matches increases and labor market tightness declines. An increase in $\varphi$ directly increases labor costs, which reduces incentives for job creation but makes it affordable to close later. At the same time, profits fall, so the job must last longer in equilibrium in order for cumulated profits to cover the firing cost.

- An increase in F, the firing cost, shifts PP to the right and WW

\footnotetext{
${ }^{9}$ They are discounted at the closing date of the firm and expressed in productivity units at that time.
} 


\section{Figure 2a}

Impact of an increase

in worker's weight

in bargaining

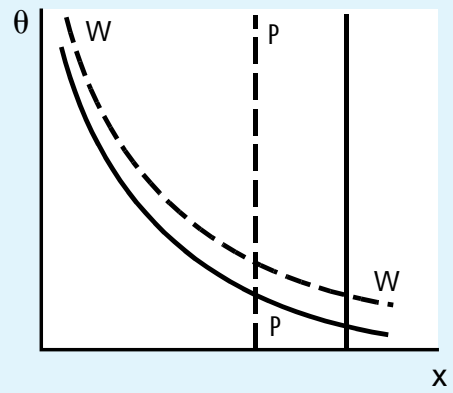

\section{Figure $2 \mathrm{~b}$}

Impact of an increase in firing costs

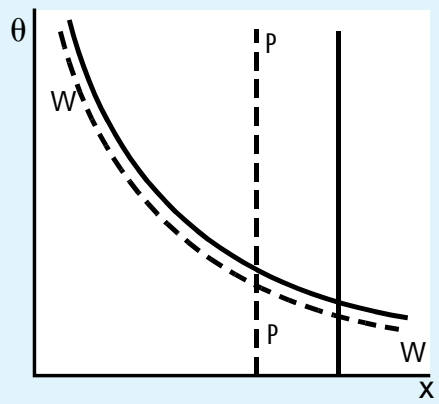

\section{Figure 2c}

Impact of an increase in the growth rate

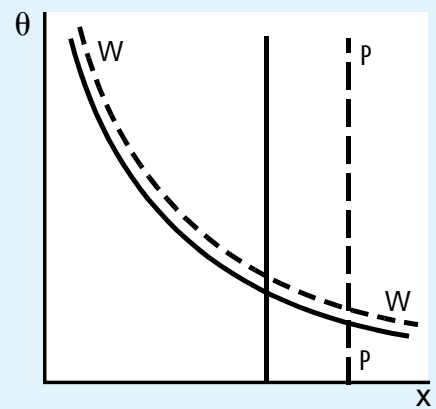

upward, (Figure 2b). A higher firing cost makes it optimal to postpone the closing time, and jobs must last longer for cumulated profits to cover the firing cost. Despite the upward shift in WW, $\theta$ unambiguously falls: Labor market tightness is reduced as increased firing costs discourage hirings. The upward shift in WW simply means that at any given job duration, one would require higher wages and therefore tighter labor markets for closing to be optimal.

- An increase in g, the growth rate, unambiguously shifts PP to the left while WW shifts down (Figure 2c). Faster growth increases the pace of obsolescence via more rapid wage growth within existing matches, and also because the growth of firing costs is faster, as they are indexed on the economy's average productivity level. The incentives to fire are therefore increased: Matches are shorter (PP shifts to the left), while the degree of labor market tightness that makes it optimal to fire falls (WW shifts down). The net effect on $\theta$ is ambiguous as $W W$ is downward sloping.

Next, it is possible to characterize the equilibrium unemployment rate and the steady-state distribution of employment across vintages. In steady state, the density of employment in firms aged $z$ is constant and equal to $1 / x$. If I is total employment, then the number of jobs destroyed per unit of time is $I / x$. In steady state, this must be equal to the outflow from unemployment, which is equal to $\theta(1-1)$. This allows us to compute the unemployment rate as a function of $\theta$ and $\mathrm{x}$ :

$$
u=\frac{1 / x}{\theta+1 / x}=\frac{1}{1+x \theta} .
$$

It should be noted that unemployment is not necessarily higher when firing costs are lower. A lower firing cost increases $\theta$, 
which tends to reduce $u$, but reduces $x$, which tends to increase $u$. Job creation is higher but so is job destruction, so unemployment may either rise or decline. This is well known from the analysis of firing costs. ${ }^{10}$

One can further compute aggregate output in steady state. It is simply equal to the product of employment and average productivity. Given that employment is uniformly distributed over all vintages, the latter is simply equal to

$$
\frac{a_{t} \int_{0}^{x} e^{-g u} d u}{x}=a_{t} \frac{1-e^{-g x}}{g x} .
$$

At any point in time t output is therefore equal to

$$
y_{t}=a_{t} \frac{\theta}{1+x \theta} \frac{1-e^{-g x}}{g} .
$$

N ote that in the extreme case, where the firing cost goes to zero, so does $\mathrm{x}$, while $\theta$ goes to infinity. The labor market converges to a situation where both the job creation rate and the job destruction rate are infinite. As technology changes continuously and is embodied into new vintages, it is optimal to close firms an instant after they have been created. As a result, people move constantly between employment and unemployment: It is as if unemployment were equally shared among the workforce. Furthermore, because of free entry, the wage is al ways equal to $a_{t}$, the state-of-the art productivity, and is higher than it would be for any positive level of the firing cost.

With that discussion, we conclude the characterization of equilibrium. We now proceed and discuss voting on firing costs.

\section{VOTING ON FIRING COSTS}

In the sequel, we will assume that society votes once and for all between two alternatives: a "rigid" society associated with a firing cost $F_{R}$ and a plant life $x_{R}$, and a "flexible" society associated with $F_{F}<F_{R}$ and $x_{F}<x_{R}$. Therefore, we assume that there are only two alternatives, reflecting the fact that there is some indivisibility in the design of legislation and that political agendas are often formulated in a binary fashion. We will typically consider that the status quo is the "rigid society," so that initially workers are distributed over plants aged between 0 and $x_{R}$. We al so assume, for simplicity, that when we do comparative statics the underlying values of the firing costs $F_{R}$ and $F_{F}$ are altered so as to maintain the two options invariant in terms of plant duration.

\section{The Shape of Preferences for Employment Protection}

The first step is to compute the utility of the employed and unemployed voters as a function of the collectively decided firing cost. The utility of the unemployed is given simply by the present discounted value of the alternative wage, that is, of the first two terms in 8 . Its value is

$$
\begin{aligned}
V_{u}(t ; x)= & \frac{a_{0} e^{g t}}{r-g} \\
& \times\left(b+\theta \varphi \frac{1-e^{-r x}}{r}\right) .
\end{aligned}
$$

As future alternative wages grow at rate $g$, this stream of income is discounted at rate $r-g$. Substituting in the equilibrium conditions, equations 9 and 10, we see that this is equivalent to

$$
\begin{aligned}
V_{u}(t ; x)= & \frac{a_{0} e^{g t}}{r-g}(1-\varphi) \\
& \times\left(1-g \frac{1-e^{-r x}}{r}\right)
\end{aligned}
$$

This formula allows us to express the utility of the employed as a function solely of the equilibrium value of plant's lifetime, $x$.

As for the utility of employed workers, it depends on which plant they are working at. The older the plant, the lower the time left for reaping their rent, and the
${ }^{10}$ Bentolila and Bertola (1990). 
lower their utility. More precisely, an employed's utility is the sum of an unemployed's utility and the present discounted value of the employed's share of the gross surplus between now and the closing time. The corresponding value is

$$
\begin{aligned}
V_{e}(z, t ; x)= & a_{0} e^{g t}\left[\left(1-g \frac{1-e^{-r x}}{r}\right) \frac{1-\varphi}{r-g}\right. \\
& \left.+\varphi e^{-g z} \frac{1-e^{-r(x-z)}}{r}\right] ; z \leq x
\end{aligned}
$$

The last term in the brackets represents the present discounted value of the rent to be earned until the current job elapses. It is larger, the larger the voted value of $x$, and smaller, the larger the current age of the job $z$.

It is important to note that equation 13 is only valid if $x \geq z$. Once people have voted on $x$, all firms with age $z>x$, if any, instantaneously disappear and fire their workers. Therefore, the utility of any worker in a plant older than $\mathrm{x}$ is by definition equal to the utility of an unemployed:

$$
V_{e}(z, t ; x)=V_{u}(t, x), z \leq x .
$$

In equations 12 and $13, \mathrm{~F}$ is treated as a function of $x$ as defined by equation 10; that is, voting on $F$ or voting on $x$ are equival ent given the relationship between the two that must hold in equilibrium. In the sequel, we find it easier to consider that workers actually vote between two values of $x$.

How do, now, the preferences of the people for firing costs depend on their labor market status? Beginning with the unemployed, equation 12 clearly implies that their utility is strictly decreasing with $x$. The unemployed prefer the lowest possible value of $x$ (or, alternatively, $F$ ). In the $F=0$ equilibrium, people move constantly between employment and unemployment so that it is as if the total amount of work were shared perfectly among people. The incumbent employee's advantage for tomorrow's jobs is eliminated; as this equilibrium yields the highest probability of finding a job and the highest wage, it is the one preferred by the unemployed.

Turning now to the employed, equation 13 implies that their utility is al ways decreasing with $z$ and increasing with $x$ if and only if

$$
e^{(r-g) z}>\frac{g(1-\varphi)}{\varphi(r-g)}
$$

For any given $\mathrm{x}$, workers in older firms have a lower utility than workers in younger firms, as they expect their rent from employment to be exhausted earlier.

The marginal gain from increasing firing costs is larger, the older the vintage where the worker is working. This is because the remaining duration of their job increases more, in proportional terms, than those of workers at younger plants. Consequently, a marginal increase in firing costs would be supported by those workers whose vintage is greater than a critical $z^{*}$, defined by

$$
z^{*}=\frac{\ln \left(\frac{g(1-\varphi)}{\varphi(r-g)}\right)}{r-g} .
$$

This property tells us that in some sense workers at ol der plants like firing costs better, but it should be remembered that we actually rule out voting on a marginal increase in firing costs as we only consider two alternatives.

Note that if

$$
\varphi>g / r,
$$

then the numerator is negative (or equivalently, the right-hand side of 14 is lower than 1), which implies that all employed workers benefit from a marginal increase in firing costs.

In the sequel, we shall assume that condition 15 holds, and discuss the case $\varphi>g / r$ later.

Figure 3 illustrates how preferences depend on $x$ for various types of workers in the case where $\varphi>g / r$. The down- 
ward sloping curve $C_{u}$ represents the preferences of an unemployed worker. $C_{0}$ represents the preferences of a worker at a newly created plant. $C_{z}$ represents the utility of a worker at a plant of age $z$ for $x>z$. It is important to note that for $\mathrm{x}<\mathrm{z}$, his utility is given by $\mathrm{C}_{u}$. $C_{z^{\prime}}$ represents the utility of a worker with $z^{\prime}>z$. As $z$ increases, $C_{z}$ shifts down and its slope shifts up. While people employed at old plants enjoy firing costs more at the margin than people working at new plants, they also are increasingly unhappy as the age of their plant increases.

\section{Voting Between Two Values of the Firing Cost}

We now turn to the question of who will favor flexibility and who will oppose it when people choose between $x_{R}$ and $x_{F}$. Figure 3 is a useful starting point. As the unemployed's utility is monotonically decreasing in $x$, they clearly support the lowest value of the firing cost. What about the employed? They typically split into two groups, as illustrated in Figure 4. There exists a critical plant age $\tilde{z}$ such that workers in plants older than $\tilde{z}$ favor flexibility while workers below $\tilde{z}$ favor rigidity. In the rigid society, workers at plants of age $\tilde{z}$ get exactly the same utility as an unemployed worker of the flexible society.

Workers of the first group are in a match that is about to expire. They have consumed most of their rent and expect to be soon unemployed and to suffer from the low job creation rate and the low productivity of the economy. They would be better off either with an increase in firing cost beyond $x_{R}$, but such an increase is not on the political agenda, or with a decrease in firing costs. Thus, if the status quo is the rigid society, they end up voting for the flexible one. The reason why this "Iost generation" prefers flexibility is that they will soon be constrained to a "new start" anyway, and the flexible society is the one that gives them the best chances. If the status quo is the flexible society, this group would not exist since $\tilde{z}$ is al ways greater than $\mathrm{x}_{\mathrm{R}}$.

\section{Figure 3}

Preferences according to plant age and employment status

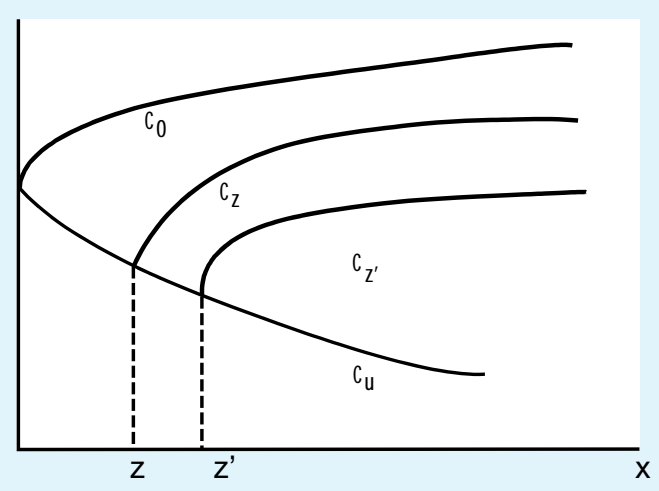

\section{Figure 4}

Interest groups among the employed, $\varphi>g / r$

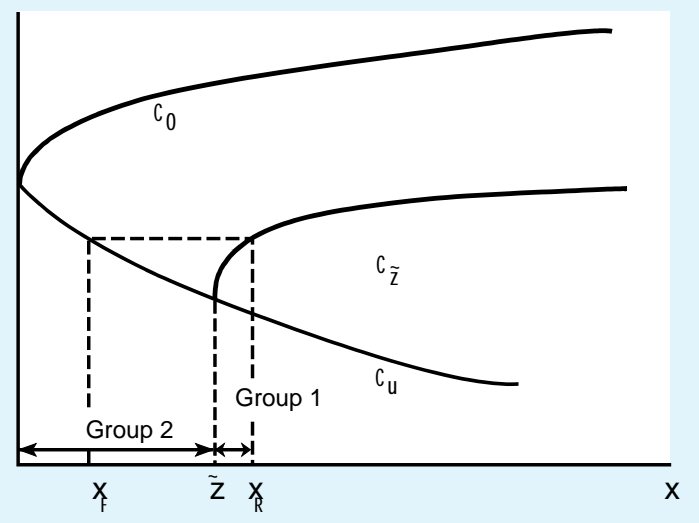

Workers such that $x_{F}<x<\tilde{z}$ prefer to maintain the rigid society: They will lose their jobs if the economy were to shift to flexibility, and their jobs will last long enough to make rigidity worthwhile for them. Workers such that $x<x_{F}$ will not lose their jobs if the economy becomes flexible. They prefer the rigid society because it increases the length of time over which they reap their rent, while the prospects of job loss is too remote for them to worry about the low rate of job creation. 


\section{Effects of Growth and Workers' Bargaining Power}

How do the parameters of the model affect the outcome? The two parameters in which we are most interested are $\varphi$, the workers' bargaining power, and $g$, the growth rate.

To analyze the effect of these parameters, it is useful to distinguish between three groups: those who work at a vintage young enough $\left(z<x_{F}\right)$ so that they would be employed in both the rigid and the flexible world; the unemployed; and those who are employed in the rigid world but would lose their job if society decided to become flexible $\left(z>x_{F}\right)$. Let us start with an increase in the workers' bargaining power $\varphi$. In general, for a given $F$, a change in $\varphi$ affects $x$. Now, for simplicity, we assume that the two alternatives are specified in terms of $x$ rather than $F$. That is, we assume that the two job lengths $x_{R}$ and $x_{F}$ do not change. As equation 13 shows, an increase in $\varphi$ reduces the first term in brackets - the value of being unemployed- but increases the second term-the rent. As rents are higher, incumbent employees are more in favor of employment protection.

Consider workers that would be employed in both worlds, that is, such that $z<x_{F}$. Their net gain from being in the rigid world instead of the flexible one is

$$
\begin{aligned}
G_{e}(z, t ; x) & =V_{e}\left(z, t ; x_{R}\right)-V_{e}\left(z, t ; x_{F}\right) \\
& =\left(\frac{\mathrm{e}^{-r x_{F}}-e^{-r x_{R}}}{r}\right) \\
& \times\left(\varphi e^{(r-g) z}-\frac{1-\varphi}{r-g} \frac{g}{r}\right) a_{0} e^{g t} .
\end{aligned}
$$

This is clearly increasing with $\varphi$. As for the unemployed, their welfare difference between the two economies is

$$
\begin{gathered}
G_{u}(t ; x)=V_{u}\left(z, t ; x_{R}\right)-V_{u}\left(z, t ; x_{F}\right) \\
=-\left(\frac{e^{-r x_{F}}-e^{-r x_{R}}}{r}\right) \frac{1-\varphi}{r-g} \frac{g}{r} a_{0} e^{g t} .
\end{gathered}
$$

Their net loss from rigidity is decreasing with $\varphi$. As $\varphi$ increases, other labor market rigidities are more important relative to firing costs in reducing the unemployed's job prospects so that their welfare loss between the high and low firing cost societies is actually reduced.

Finally, those workers who would lose their jobs if the economy were to shift from rigidity to flexibility have a gain from flexibility equal to

$$
\begin{aligned}
G_{e}^{\prime}(z, t ; x)= & V_{e}\left(z, t ; x_{R}\right)-V_{u}\left(z, t ; x_{F}\right) \\
=\mathrm{a}_{0} \mathrm{e}^{\mathrm{gt}}[ & -\left(\frac{\mathrm{e}^{-\mathrm{rx}}-\mathrm{e}^{-\mathrm{rx} \mathrm{R}}}{\mathrm{r}}\right) \frac{1-\varphi}{\mathrm{r}-\mathrm{g}} \frac{\mathrm{g}}{\mathrm{r}} \\
& \left.+\varphi \mathrm{e}^{-\mathrm{gx}} \frac{1-\mathrm{e}^{-\mathrm{r}\left(\mathrm{x}_{\mathrm{R}}-\mathrm{z}\right)}}{\mathrm{r}}\right] \\
= & \left(\mathrm{V}_{\mathrm{u}}\left(\mathrm{z}, \mathrm{t} ; \mathrm{x}_{\mathrm{R}}\right)-\mathrm{V}_{\mathrm{u}}\left(\mathrm{z}, \mathrm{t} ; \mathrm{x}_{\mathrm{F}}\right)\right) \\
& +\left(\mathrm{V}_{\mathrm{e}}\left(\mathrm{z}, \mathrm{t} ; \mathrm{x}_{\mathrm{R}}\right)-\mathrm{V}_{\mathrm{u}}\left(\mathrm{z}, \mathrm{t} ; \mathrm{x}_{\mathrm{R}}\right) .\right.
\end{aligned}
$$

This is the sum of the (negative) welfare gain of the unemployed, which, as we have seen, increases with $\varphi$ and the employee's rents in the rigid economy, which also clearly increase with $\varphi$. Thus, these people gain more, or lose less, from rigidity when $\varphi$ increases.

Therefore, in an economy with a high value of $\varphi$ - powerful employees- a given individual, whether working in a plant of any age $z$ or unemployed, will al ways be more in favor of rigidity than in a world were $\varphi$ is low. Is it obvious, then, that the political support for the rigid society is greater? The answer is no. For it is al so true that unemployment is higher when $\varphi$ is large, which tends to push up the number of people who oppose rigidity, even though these people lose less from rigidity than if $\varphi$ were small. What is clear, however, is that within the employed, the support for rigidity increases, meaning that the critical plant age increases. ( $\tilde{z}$ must satisfy $G_{e}^{\prime}(\tilde{z}, t ; x)=0$, and that function is decreasing with $z$ and shifts up when $\varphi$ increases.) If labor market institutions were mostly determined by the employed, say because they are 
better organized collectively or because the unemployed have a low rate of participation in elections, then the political support for rigidity would unambiguously increase when $\varphi$ rises. Another way to put it is to say that controlling for the unemployment rate, the high firing cost is more likely to be chosen when $\varphi$ is higher.

W hat happens, now, when the growth rate is larger? If we compare the high growth economy and its low growth counterpart at two points in time when they have the same technological level, which amounts to holding $\mathrm{a}_{0} \mathrm{e}^{\mathrm{gt}}$ constant in our comparisons, the above formulae imply that an increase in $g$ reduces $G_{e^{\prime}} G_{u}$ and $G_{e}^{\prime}$. Consequently, faster growth unambiguously reduces the political support for employment protection if we hold the stock of unemployment constant.

The growth rate acts in two ways. First, it increases the obsolescence rate and, therefore, the deadweight cost of maintaining relatively unproductive matches idle. This in itself reduces the support for employment protection. Second, faster growth tends to reduce the effective discount rate applied to the future: Incumbent workers put more weight on the lower job finding rate they will experience once their current match is dissolved, because future jobs pay more. This al so tends to reduce the support for employment protection.

\section{The $\varphi<\mathrm{g} / \mathrm{r}$ Case}

W hat happens now if $\varphi<g / r$ ? Equation 14 implies that workers with sufficiently small z will have a utility strictly decreasing with $x$. As illustrated on Figure 5 , the flexible society is preferred by a group of workers who work in the most recent plants. These workers lose more, in terms of lower wages, than they gain in terms of a postponed dismissal. There are now three interest groups among the employed. Those who work at plants younger than $z^{*}$ have a utility that is decreasing with the firing cost, so that they will al ways prefer the flexible economy. Those who work at

\section{Figure 5}

Three groups in the $\varphi<\mathrm{g} / \mathrm{r}$ case

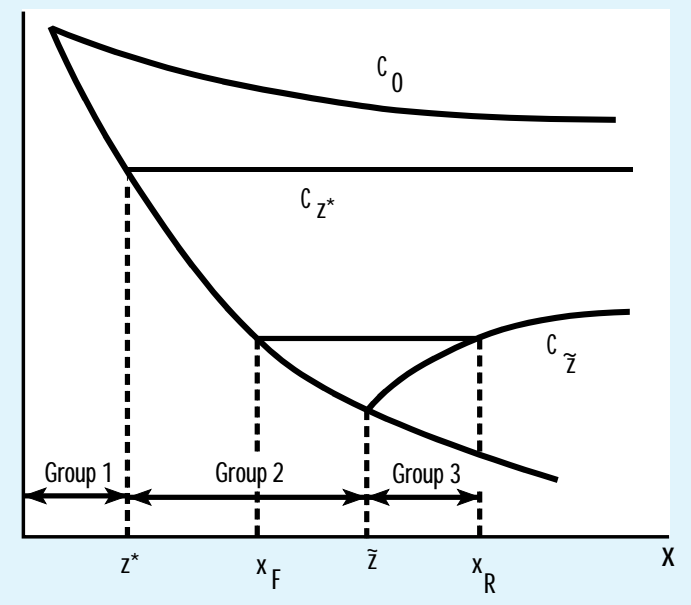

plants older than $\tilde{z}$ are about to lose their jobs and oppose rigidity for the reasons al ready explained. Those who work in plants between $z^{*}$ and $\tilde{z}$ gain more from rigidity than what they lose. Thus, among the employed, labor market reform (in the sense of a deregulation) would be supported by an "extreme coalition" of people working in either the most dynamic plants or plants that soon will become obsolete.

Another property of this case is that the maximum welfare point is actually attained at $x=0$. Since workers at young plants are always happier, given $x$, than workers at old plants, and since those at plants just created $(z=0)$ have a utility which is decreasing with $x$, there would be unanimity in favor of a zero firing cost, if this is a feasible outcome.

Conversel $y$, if the status quo is $x=0$ then all employed workers work in plants of age $z=0$. A necessary condition for zero firing costs to remain a political equilibrium is therefore that workers at plants with $z=0$ would be worse off if firing costs were higher, which given equation 14 , is precisely equivalent to $\varphi<g / r$.

Therefore, for a "flexible" society to be stable (in the sense that people will not want to change its institutions), it must be the case that the worker's share 
of the surplus does not exceed the ratio between the growth rate and the interest rate. This simple formula (which we are tempted to label the "golden rule of flexibility") is a useful shortcut for thinking about the determinants of the political support for flexibility.

\section{ASSESSING THE VIABILITY OF LABOR MARKET REFORMS: DO GOVERN- MENTS REDUCE FIRING COSTS WHEN BARGAINING POWER IS LOW?}

The above analysis suggests that there are three important determinants of reform, namely the workers' bargaining power, the growth rate, and the interest rate. It is, therefore, tempting to take these predictions to the data and see how they square with reality. Now the question arises of how literally one can interpret our results. For example, the importance of the growth rate, in our analysis, captures the role of the rate of renovation of old plants in the long run. By contrast, macroeconomic data on growth mostly capture cyclical fluctuations and changes in the underlying trend of productivity that may not be associated with changes in creative destruction. The real interest rate may not play a big role if incumbent employees have only an imperfect access to capital markets.

Furthermore, what is relevant for

${ }^{11}$ See Bentolila and Saint-Paul (1998) for more details.

${ }^{12}$ Again, we refer the reader to Bentolila and Saint-Paul (1998) for a detailed analysis.

${ }^{13}$ See Saint-Paul (1996b) for a discussion of these reforms and their determinants. In that paper, I actually ignore the role of workers' rent, focusing on the employed's exposure to unemployment and on the number of unemployed workers as factors important for the viability of reform. approach would be to take the share of labor in national income. This share, however, typically reflects other phenomena as well, such as variations in factor inputs as a reaction to changes in factor prices. Bentolila and Saint-Paul (1998) show that such movements are associated with a relationship between the labor share and the capital/output ratio. To proxy for workers' bargaining power, we just take the residual of a first-difference regression of the labor share on the capital/output ratio. ${ }^{11}$ Our results are conditional on the validity of that proxy, which clearly may be questioned. The capital/output ratio filters out many sources of movements of the labor share unrelated to bargaining power, but other sources remain. ${ }^{12}$ One should also keep in mind that our measure is positively related to the economic cycle, so that correlation between that measure and the timing of reforms may also capture other mechanisms. The results we present, therefore, should be interpreted with caution.

Figures 6 through 10 represent the evolution of our measure of the workers' bargaining power for the five largest European countries. These figures are not comparable across countries and the initial value cannot be interpreted. Only the evolution within each country is meaningful.

The evolution of our measure is somewhat related to the reforms that actually took place.13 For example, in Spain, our measure dropped sharply between 1978 and 1984, suggesting the opening of a "window of opportunity" for reducing firing costs in 1984. It is precisely that year that a major reform was introduced with the liberalization of the use of temporary contracts. Prior to that reform temporary contracts mostly were restricted to work of temporary nature, as in many other European countries, and temporary contracts only accounted for 10 percent of the workforce. In 1984, however, the government made it possible to use those contracts over a wide range of circumstances. This amounted to a substantial reduction of firing costs as employers could simply hire a worker on a temporary contract 
and fail to renew that contract when it expired if they wanted to get rid of the worker. The graph for Spain tells us that this reform came into effect at a time when the rent of the employed had substantially declined from the peak it had reached in the mid-seventies, so that the resistance of the insiders to such a reduction in firing costs was considerably lower than if one had attempted to implement it in, say, 1980.

In the United Kingdom, the fall in workers' bargaining power apparently occurred earlier than in Spain, so that the window of opportunity began in the late seventies/early eighties. Again, this squares with our theory, because this interval coincides with the rise to power of a conservative government, who subsequently engaged in comprehensive labor market reform, including a reduction of firing costs. Note that despite these reforms, workers' bargaining power seems to go up again thereafter; this captures the high wage inflation of the second half of the eighties, but there was no reversal of the reforms.

In France, the decline of workers' bargaining power occurs somewhat later than in Spain and the U.K.; but again, the opening of the window of opportunity, 1986, coincides with the rise to power of a conservative government and a reduction in firing costs- namely, the suppression of the compulsory administrative approval for layoffs, which was established in 1974 (at a time of rising bargaining power but before it reached its peak). Our proxy, on the other hand, fails to account for an increase in firing costs that was implemented in 1989 when the Left returned to power.

Reforms that reduce firing costs have been much milder in Germany than in Spain, perhaps reflecting a society that needs greater consensus to move ahead and is, therefore, more likely to stay where it is. Nevertheless, the timing of the reform matches our analysis well. As in Spain, temporary contracts were liberalized in 1984 (although this was much more timid than in Spain), after a sharp drop of our estimated workers'

\section{Figure 6}

Worker's Bargaining Power, Spain

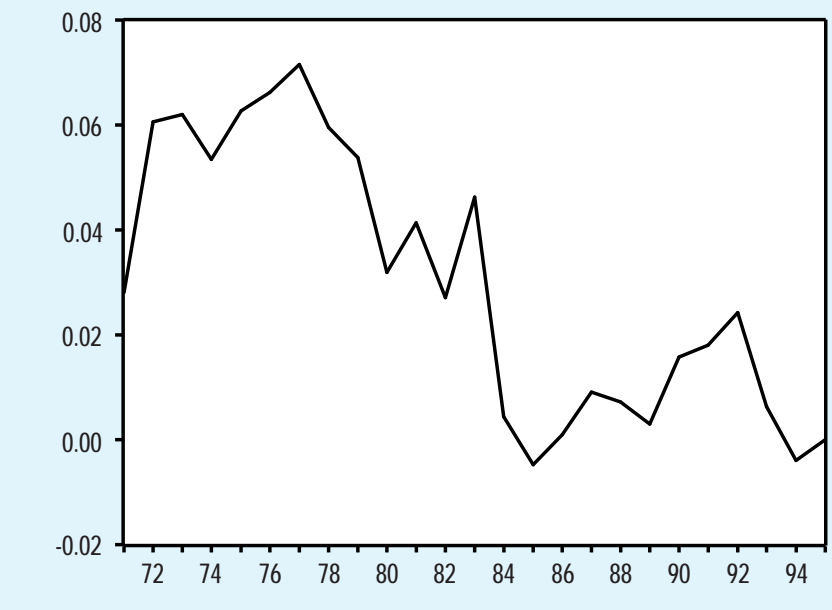

\section{Figure 7}

Worker's Bargaining Power, U.K.

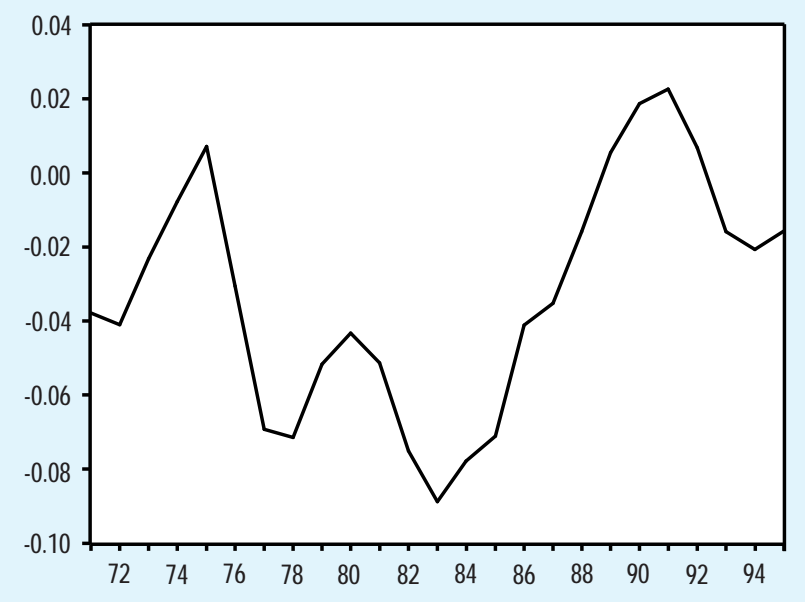

bargaining power.

Of all the countries we deal with, Italy is the one most characterized by "stop-and-go" policies. Reductions in firing costs alternate frequently with increases in firing costs. For that reason, one should not expect our proxy to work too well. But, in fact, it does a reasonable job at explaining the twists of policy. Firing costs were reduced in 1977, 1984, 


\section{Figure 8}

Worker's Bargaining Power, France

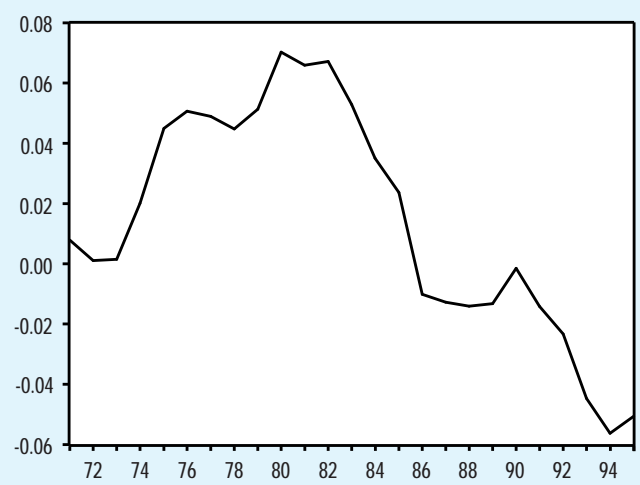

\section{Figure 9}

Worker's Bargaining Power, Germany

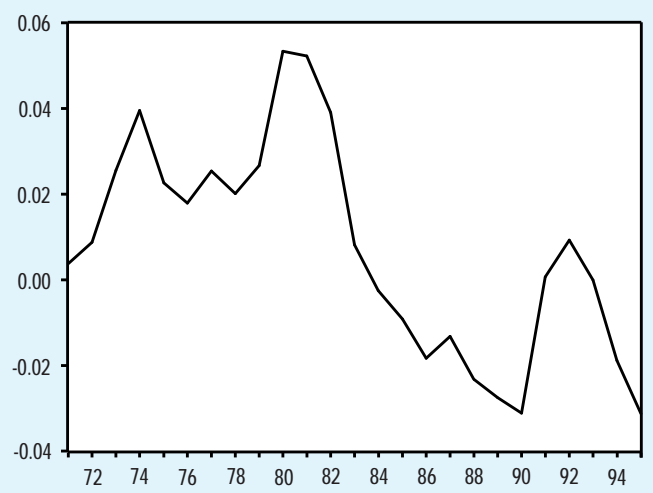

\section{Figure 10}

Worker's Bargaining Power, Italy

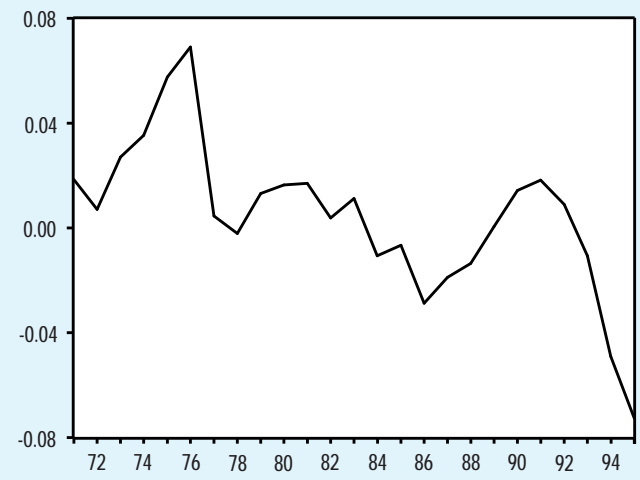

1986, and 1987, following drops in our measure of the bargaining power. They were increased in 1989 and 1990, at times when the employed's rent appears to be high. Finally, there was a further reduction in firing costs in 1991, a move that our proxy clearly fails to predict.

Obviously, this evidence is only indicative and leaves a lot of room for qualifications, al ternative interpretations, and further research. However, it is suggestive that one can actually identify some regularities in the timing of labor market reforms.

\section{CONCLUSION}

In this paper, we have studied the circumstances under which there will be sufficient support for a high level of employment protection. We have argued that two key determinants of such support are the employed's share in bargaining and the rate of growth of the economy. The political viability of a reduction in firing costs is highest for low levels of the employee's share and or high growth rates. The prediction of our model bears some resemblance to the real world's experience, although one cannot hope for sharp empirical tests when dealing with political-economy models.

\section{REFERENCES}

Bentolila, Samuel and Giuseppe Bertola. "Firing Costs and Labour Demand: How Bad is Eurosclerosis?" Review of Economic Studies (July 1990), pp. 381-402.

, and Gilles Saint-Paul. "Explaining Movements in the Labor Share," Centre for Economic Policy Research, Discussion Paper No. 1958, September 1998.

Blanchard, Olivier, and Pedro Portugal "What Hides Behind an Unemployment Rate: Comparing of Portuguese and U.S. Unemployment," mimeo, MIT, June 1998.

Caballero, Ricardo and Mohamad Hammour. "The Cleansing Effect of Recessions," American Economic Review (December 1994), pp. 1350-68.

Cohen, Daniel, Arnaud Lefranc, and Gilles Saint-Paul. "French Unemployment: A Transatlantic Perspective," Economic Policy: A European Forum (October 1997), pp. 265-85.

Mortensen, Dale and Christopher Pissarides. "Job Creation and Job Destruction in the Theory of Unemployment," Review of Economic Studies (July 1994), pp. 397-415. 
OECD. The OECD Jobs Study, Paris: OECD, January 1995.

Saint-Paul, Gilles. "On the Political Economy of Labor Market Flexibility," NBER Macroeconomics Annual 1993, Cambridge: MIT Press, 1993, pp. 151-87. the Middle Class," International Tax and Public Finance (July 1996a), pp. 385-95.

. "Exploring the Political Economy of Labour Market Institutions," Economic Policy: A European Forum (October 1996b), pp. 263-300.

"The Rise and Persistence of Rigidities," American Economic Review (May 1997), pp. 290-94.

"The Political Economy of Firing Costs," mimeo, Universitat Pompeu Fabra, Barcelona, October 1998. 
MARCH/ APRIL 1999

FEDERAL RESERVE BANK OF ST. LOUIS 